\title{
Chronic khat (Catha edulis) and alcohol marginally alter complete blood counts, clinical chemistry, and testosterone in male rats
}

This article was published in the following Dove Press journal:

Journal of Experimental Pharmacology

22 June 2013

Number of times this article has been viewed

Paul E Alele'

Abayrence Imanirampa'

'Department of Pharmacology and Therapeutics, Faculty of Medicine, Mbarara University of Science and Technology, Mbarara, Uganda; ${ }^{2}$ Department of Pharmacology and Toxicology, Faculty of Biomedical Sciences, Kampala International University - Western Campus, Bushenyi, Uganda
Correspondence: Paul E Alele Department of Pharmacology and Therapeutics, Faculty of Medicine, Mbarara University of Science and Technology, PO Box 14I0,

Mbarara, Uganda

Tel +256 773573372

Fax +256485420782

Email paulalele@must.ac.ug
Introduction: Khat (Catha edulis) is a recreational psychoactive drug with psychostimulant properties. While the use of this drug is widespread in eastern Africa, including the Horn of Africa, surveys and anecdotal data show that its use has become cosmopolitan, with users now living in Europe and North America as well. Recent data in Uganda suggest an increasing pattern of simultaneous khat and ethanol use particularly among young adults. However, the effects of this pattern of use remain largely unknown, even though long-term use of either drug alone is known to be harmful. The aim of this study was to examine the toxic effects of simultaneous chronic administration of khat and ethanol on hematological parameters, clinical chemistry, and testosterone in a rat model.

Methods: Adult male Sprague-Dawley rats were randomly assigned to one of six dose groups: $2 \mathrm{~g} / \mathrm{kg}$ khat; $4 \mathrm{~g} / \mathrm{kg}$ khat; $4 \mathrm{~g} / \mathrm{kg}$ ethanol; combined khat and ethanol (4 g/kg each); control; and an untreated group. Treatments were given by gavage twice daily for 28 days, followed by determination of hematological parameters, blood clinical chemistry, and testosterone.

Results: Ethanol alone significantly reduced platelet counts compared to control-, untreated and low-dose khat-treated rats; conversely low-dose khat significantly increased both the hemoglobin and hematocrit values, while ethanol alone also significantly increased the hemoglobin value compared to controls. Simultaneous khat and ethanol administration per se did not produce more toxic consequences in chronic use than either drug alone.

Conclusion: Chronic short-term khat use and ethanol dependence individually produce noteworthy effects on the blood, but not on clinical chemistry or testosterone. Chronic short-term combined khat and ethanol use does not produce more toxic effects compared to use of either drug alone. This provides an opportunity for appropriate clinical interventions to avert the chronic long-term effects that result from use of these drugs of abuse.

Keywords: khat, ethanol, hematology, chemistry, testosterone, chronic

\section{Introduction}

Khat (Catha edulis), a plant with a natural distribution in East Africa and the Arabian Peninsula, is harvested almost year-round and its tender leaves and twigs chewed for their euphoriant effects. Chewing of khat has presently become cosmopolitan because of air transport and the migration of ethnic populations that traditionally chew khat., ${ }^{1,2}$ The ingestion of khat produces sympathetic activation characterized by euphoria, increased intellectual efficiency and alertness, anxiety, high blood pressure, and other effects. ${ }^{3}$ These effects are mainly mediated by phenylalkylamines such as cathinone (the major stimulant) and cathine, although several other stimulant compounds are also found in khat. ${ }^{3}$ Recent studies in Uganda and elsewhere have shown that many individuals chew khat and drink alcohol (ethanol) concurrently. ${ }^{4-8}$ It is established that 
khat produces psychological and physical dependence on long-term use, ${ }^{9}$ and chronic use of khat is associated with the development of several systemic and metabolic disorders.

In young adults, the chronic use of khat is associated with hypertension, as well as stomatitis, esophagitis, gastritis, and constipation. ${ }^{10}$ Notably, an association has been found between khat chewing and acute coronary syndrome, a syndrome that results from coronary artery spasm and produces myocardial infarction. ${ }^{11-13}$ Other cardiovascular disorders, for example cardiovascular ischemia, thromboembolism, and dilated cardiomyopathy, have also been associated with khat chewing. ${ }^{13}$ Additionally, khat use has been associated with metabolic disorders such as diabetes mellitus, and with the development of hepatitis and liver cirrhosis. ${ }^{14}$ Moreover, khat use has been associated with anaphrodesia among male users who noted a loss of sexual drive and subsequent impotence after a brief and initial increase in libido associated with khat use. ${ }^{15}$ Prior animal studies have indicated that cathinone can depress testosterone levels and produce degeneration of testicular tissue and decreased sperm count and motility, ${ }^{16}$ and that khat extracts can alter testosterone levels in a dose-dependent manner. ${ }^{17}$

In its most recent assessment of the burden of global alcohol use, the World Health Organization estimates that men have far greater total burden rates attributable to alcohol than women (7.4\% for men compared to $1.4 \%$ for women), with men outnumbering women in a $4: 1$ ratio in weekly episodes of heavy drinking. ${ }^{18}$ Consequently, men suffer more deaths - globally, $6.2 \%$ of all male deaths are attributable to alcohol, compared to $1.1 \%$ of all female deaths. Furthermore, harmful alcohol use is the leading risk factor for death in men aged 15-59 years, mainly from injuries, violence, and cardiovascular diseases. ${ }^{18-21}$ Despite the known harmful consequences of alcohol abuse and dependence, attention and action to mitigate harm remain a low priority in health and public policy in many countries. ${ }^{18}$

The goal of this study, therefore, was to determine the effects of khat and ethanol on blood counts, liver function, and testosterone, and to address the question of whether concurrent chronic but short-term use of khat and ethanol can produce greater toxic effects on these markers than use of either drug alone. Because the effects of simultaneous khat and ethanol consumption are largely unknown, it is important to study these effects in order to provide evidence that can help to mitigate the toxicity induced by consumption of these recreational drugs. Evidence obtained from this study would additionally inform policy regarding the use of khat and ethanol. Therefore, the aims of this study were to (1) assess complete blood count (CBC) and indices following chronic short-term administration of both khat and ethanol and compare these parameters among the different treatment groups; and (2) determine blood clinical chemistry and testosterone following chronic short-term administration of both khat and ethanol and compare these parameters among the different treatment groups.

\section{Materials and methods Experimental design and animals}

This experimental study was a between-groups design where the difference between group means would indicate the size of the effect of treatments. Adult male Sprague-Dawley rats, approximately 8 weeks old at the start of the experiments, were fed standard laboratory chow and given water ad libitum. The animals were group-housed in polypropylene cages (four animals per cage) in a temperature-controlled $\left(23^{\circ} \mathrm{C} \pm 1^{\circ} \mathrm{C}\right)$ research facility with a $12: 12$ hour light:dark cycle (lights on at $6 \mathrm{am}$ ). Following one week of acclimation, the animals were assigned to one of six dose groups: $2 \mathrm{~g} / \mathrm{kg}$ khat; $4 \mathrm{~g} / \mathrm{kg}$ khat; $4 \mathrm{~g} / \mathrm{kg}$ ethanol; combined khat and ethanol ( $4 \mathrm{~g} / \mathrm{kg}$ each); control; and an untreated group. All treatment assignments were randomized by computer-generated random numbers at the beginning of the experimental period. The sample size for all experiments was eight to ten animals per treatment condition. Rats were weighed twice a week to ensure appropriate dosing based on body weight changes. All treatments were given between 8 am and 10 am and repeated between 3 pm and 5 pm daily. This dosing regimen was based on earlier studies that showed reliable induction of ethanol dependence and positive reinforcement by khat. ${ }^{22}$ Additionally, because khat chewing typically occurs in the daytime, ${ }^{1,6}$ and the maximal plasma concentrations of cathinone, a major active component of khat, appear to be delayed to approximately 2 hours after oral administration, ${ }^{23}$ the dosing regimen was designed to mimic typical consumption in people who use both drugs concurrently. Treatments were given uninterrupted for 28 days as described under the Animal Treatment section below. Ethical approval was obtained from the Faculty of Medicine Research and Ethics Committee and the Institutional Ethics Review Board of Mbarara University (Approval Numbers: DMS 20/4 and 01/05-12 respectively).

\section{Phytochemical screening}

Khat extracts were prepared according to the method described for phytochemical screening of medicinal plants. ${ }^{24}$ Briefly, khat extracts were obtained by macerating a known weight of the fresh plant parts (tender leaves and twigs) with distilled water 
in an electric blender. The extract was suction-filtered and the process repeated until all soluble components had been extracted, judged by loss of colour of the filtrate. This extract contained all undegraded active components. The total extract was then evaporated to dryness at $45^{\circ} \mathrm{C}$ and further dried to constant weight at the same temperature in a hot-air oven. A separate quantity of the fresh khat was air-dried under shade and ground with a mortar and pestle. Half of the dried powder obtained was extracted with $80 \%$ methanol in a soxhlet extractor, while the other half was extracted using distilled water. The extracts were oven-dried to constant weight. Residue yield (percentage yield) was calculated as (weight of dried concentrate/initial weight of powder) $\times 100$, and a portion used in phytochemical testing for all the common phytochemicals.

\section{Animal treatment}

\section{Khat administration}

Animals that received khat were given $2 \mathrm{~g} / \mathrm{kg}$ and $4 \mathrm{~g} / \mathrm{kg}$ of khat by gavage twice daily simultaneously with the oral ethanol and control groups. The choice of these doses of khat was based on prior related studies that showed the activity of fresh aqueous khat extracts without excessive effects, ${ }^{22,25}$ and because the absorption of the active principles in khat users is thought to be limited by the bulk quantities of the khat leaves chewed. ${ }^{3}$ Khat treatment was done for 28 days.

\section{Ethanol administration}

Animals that received ethanol were given $20 \%$ ethanol by gavage at a dose of $4 \mathrm{~g} / \mathrm{kg}$ body weight. This dose of ethanol was based on data that have indicated that persons who chew khat and drink alcohol concurrently typically drink spirits and wines known to have a higher alcohol content than beer. ${ }^{6}$ Ethanol treatment was done twice daily for a total of 28 days. All treatments ended by the beginning of the active period (starting at $6 \mathrm{pm}$ for alternating 12 hour light:dark periods), during which rats are more active. Blood alcohol levels (BAL) were not measured because the twice-daily administration of ethanol would lead to variations in BAL; furthermore, because animals were not sacrificed until the morning of the day after the last administration of ethanol (and other substances), there would not be any measureable BAL at the time of obtaining trunk blood, as BAL has been found to reach zero by 6 hours after oral administration. ${ }^{26}$

\section{Control animals}

Control animals received normal saline $(4 \mathrm{~mL} / \mathrm{kg})$ only by gavage, for 28 days. An untreated animal group was included and gave an intrasystem negative control to ensure that measurements were valid by providing a point of contrast with the normal saline-treated (control) group. This ensured that the experimental system, as outlined for the other treatments, was not in itself pertubing the outcome.

\section{Measurement of hematological values and indices}

On day 29, trunk blood (approximately $4 \mathrm{~mL}$ ) from each animal of the six experimental groups was collected after sacrifice by decapitation, in a tube containing ethylenediamine tetraacetic acid to prevent blood clotting. Samples were then promptly delivered to the hematology laboratory where full blood counts, including hemoglobin, mean corpuscular hemoglobin $(\mathrm{MCH})$, mean corpuscular volume (MCV), total red blood cell (RBC) count, total plus differential white blood cell count, and platelet count, were determined. Collection of trunk blood for measurement of hematological parameters, clinical chemistry, and testosterone was done between $7 \mathrm{am}$ and $11 \mathrm{am}$.

\section{Measurement of blood clinical chemistry}

On day 29, animals were sacrificed by decapitation and trunk blood collected from each animal (approximately $4 \mathrm{~mL}$ ) of each of the six experimental groups. The blood was kept in a plain tube to allow clotting and serum separation. The samples were sent to the hematology laboratory where serum separation was done to obtain clear sera for measurement of serum amylase, alkaline phosphatase (ALP), aspartate aminotransferase (AST), alanine aminotransferase (ALT), serum albumin, creatinine, and low and high density lipoproteins (LDL and HDL). We did not measure blood glucose levels because prior studies have shown that khat has little effect on blood sugar levels. ${ }^{27}$ Clinical chemistry analysis was done using an automated analyzer (Humastar ${ }^{\circledR}$; Human Diagnostics GmbH, Wiesbaden, Germany) according to the manufacturer's instructions.

\section{Measurement of serum testosterone}

Total testosterone was measured using a Microparticle Enzyme Immunoassay (MEIA; AxSYM ${ }^{\circledR}$ Testosterone; Abbott Laboratories, Abbott Park, IL, USA). This assay displaces bound testosterone from binding proteins (sex hormone binding globulin or testosterone binding globulin and albumin) and quantitatively measures total testosterone. The AxSYM ${ }^{\circledR}$ Testosterone assay demonstrates a functional sensitivity (the lowest concentration measureable with an inter-assay coefficient of variation $\leq 20 \%$ ) of $\leq 0.2 \mathrm{ng} / \mathrm{m}$. Its analytical sensitivity (the concentration at two standard deviations above the standard control mean rate representing the lowest concentration of testosterone that can be distinguished from zero) is $\leq 0.1 \mathrm{ng} / \mathrm{mL}$. 


\section{Data analysis}

Numerical data summaries were obtained and presented graphically, followed by testing for homogeneity of variance using Bartlett's test. Thereafter, statistical testing was done using one-way analysis of variance (ANOVA) for parametric data, and Kruskal-Wallis test (non-parametric ANOVA) for data that did not meet the assumptions for 1-way ANOVA. The independent variable was treatment and comprised six levels: an untreated group; $2 \mathrm{~g} / \mathrm{kg}$ khat; $4 \mathrm{~g} / \mathrm{kg} \mathrm{khat;} 4 \mathrm{~g} / \mathrm{kg}$ ethanol; combined khat and ethanol ( $4 \mathrm{~g} / \mathrm{kg}$ each); and a control group. Outliers in the data were determined using Grubb's method (extreme studentized deviate). Data were reported as mean \pm standard error of the mean, and statistical significance was taken for $P<0.05$. Significant main effects obtained from ANOVA were further analyzed using Bonferroni's multiple comparison test to compare the treatment groups (for 1-way ANOVA), and least significant difference for KruskalWallis test. Graphing and statistical analysis was done using Microsoft Excel ${ }^{\circledR}$ (Microsoft Corporation, Redmond, WA, USA) and GraphPad Prism ${ }^{\circledR}$ version 6 (GraphPad Software, Inc, La Jolla, CA, USA) respectively.

\section{Results}

\section{Phytochemical testing}

Khat leaves and twigs contain big amounts of tannins (up to $14 \%$ dry weight); cathine is an alkaloid fraction found in small quantities $\left(0.1 \%-0.2 \%\right.$ of dried leaves) in khat. ${ }^{28}$ The phytochemical tests done were a qualitative analysis comparing the presence or absence of the different phytochemicals in the aqueous and methanol extracts. General phytochemical screening showed the presence of the major phytochemicals in the crude aqueous khat extracts (Table 1). The fresh aqueous extract tested positive for the presence of all the phytochemicals tested except for alkaloids; the dried aqueous extract tested negative for alkaloids, lactones, coumarins, steroids, and terpenoids; the dried methanol extract tested positive for all the phytochemicals tested.

\section{Body weight of experimental animals}

All animals showed a modest weight gain. There was no statistical difference between the treatment groups for body weights at the beginning of the experiment and at 28 days of treatment (Figure 1). However, on day 24, there was a trend towards a significant difference in body weights $(P=0.059)$ which persisted to day $28(P=0.062)$.

\section{Hematological values and indices}

\section{Blood counts}

White blood cell (WBC) counts, RBC counts, platelet counts and $\mathrm{RBC}$ distribution width (RDW) in male rats after 28 days of treatment with $2 \mathrm{~g} / \mathrm{kg}$ khat, $4 \mathrm{~g} / \mathrm{kg}$ khat, $20 \%$ ethanol, $20 \%$ ethanol plus khat, control, and no treatment are shown in Figure 2A-D. There were no significant differences among the treatment groups in the blood counts for WBC, RBC, and RDW. However, there was a significant effect of treatment on the platelet count in the male rats (Kruskal-Wallis $\mathrm{H}=13.61$,

Table I Screening test results for phytochemicals found in khat

\begin{tabular}{|c|c|c|c|c|}
\hline \multirow[t]{2}{*}{ Test } & \multicolumn{3}{|l|}{ Result } & \multirow[t]{2}{*}{ Deduction } \\
\hline & $\begin{array}{l}\text { Fresh aqueous } \\
\text { extract }\end{array}$ & $\begin{array}{l}\text { Dried aqueous } \\
\text { extract }\end{array}$ & $\begin{array}{l}\text { Methanolic } \\
\text { extract }\end{array}$ & \\
\hline Ferric chloride test & +++ & +++ & +++ & Tannins present in all the extracts \\
\hline Mayer's test & Negative & Negative & ++ & Alkaloids detected only in the methanolic extract \\
\hline Dragendorff's test & Negative & Negative & ++ & Alkaloids detected only in the methanolic extract \\
\hline Baljet test & + & Negative & + & $\begin{array}{l}\text { Fresh aqueous and methanolic extracts but not dried } \\
\text { aqueous extracts contain lactones, and coumarins }\end{array}$ \\
\hline Foam assay & + & + & ++ & $\begin{array}{l}\text { Steroidal or triterpenoidal saponins present in all } \\
\text { extracts; more in methanolic extract }\end{array}$ \\
\hline Liebermann-Burchard's test & + & Negative & ++ & $\begin{array}{l}\text { Fresh aqueous and methanolic extracts but not dried } \\
\text { aqueous extracts contain steroids and terpenoids; } \\
\text { more in methanolic extract }\end{array}$ \\
\hline Salkowski's test & + & Negative & + & $\begin{array}{l}\text { Fresh aqueous and methanolic extracts but not dried } \\
\text { aqueous extracts contain terpenoids }\end{array}$ \\
\hline Sudan III test & + & + & + & All three extracts contain oils and fats \\
\hline Fehling's test & + & + & ++ & $\begin{array}{l}\text { All three extracts contain simple sugars; more in } \\
\text { methanolic extract }\end{array}$ \\
\hline Ammonia test & + & +++ & +++ & $\begin{array}{l}\text { All three extracts contain flavonoids; more in dried } \\
\text { aqueous and methanolic extracts }\end{array}$ \\
\hline
\end{tabular}

Notes: The fresh aqueous extract tested positive for the presence of all the phytochemicals tested except for alkaloids; the dried aqueous extract tested negative for alkaloids, lactones, coumarins, steroids, and terpenoids; the dried methanol extract tested positive for all the phytochemicals tested. 


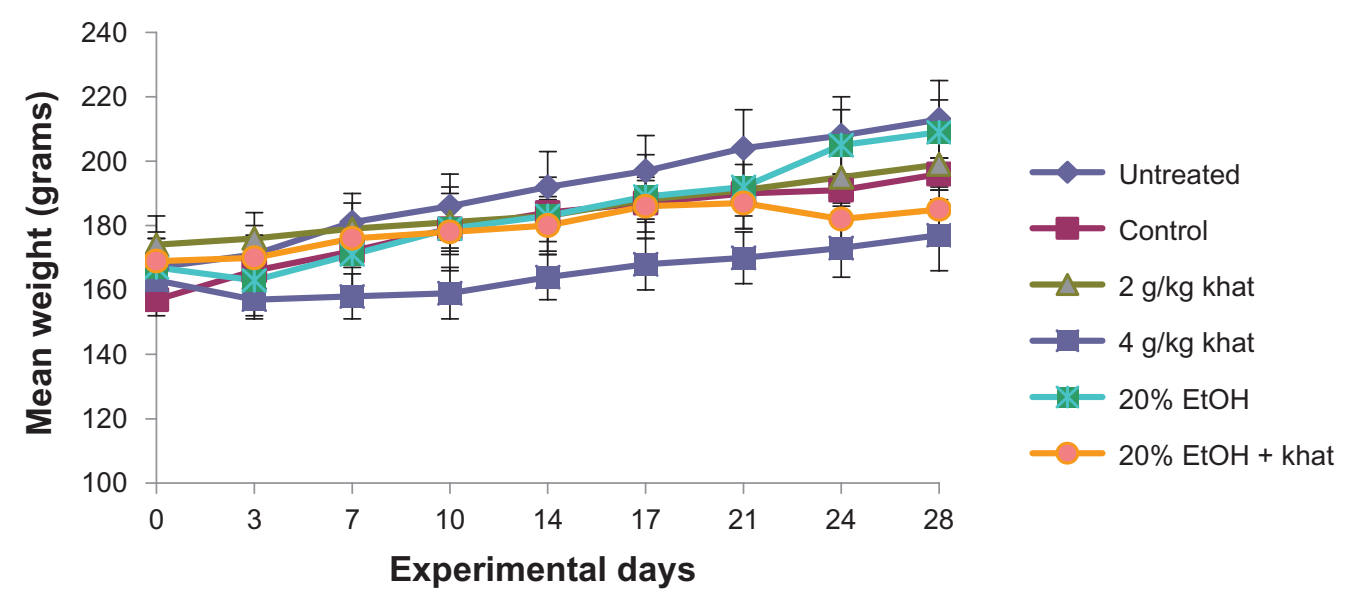

Figure I Body weights of experimental animals.

Notes: Body weights of experimental animals (grams), shown as mean \pm standard error of the mean. All animals showed a modest weight gain. There was no statistical difference in body weight between the treatment groups at the beginning of the experiment and at 28 days of treatment. However, on day 24 , there was a trend towards a significant difference in body weights $(P=0.059)$ which persisted to day $28(P=0.062)$.

Abbreviation: $\mathrm{EtOH}$, ethanol.

A

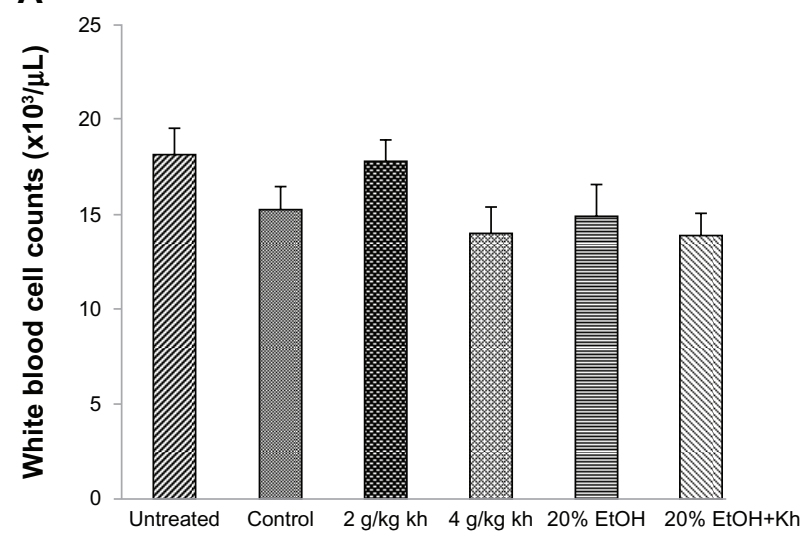

C

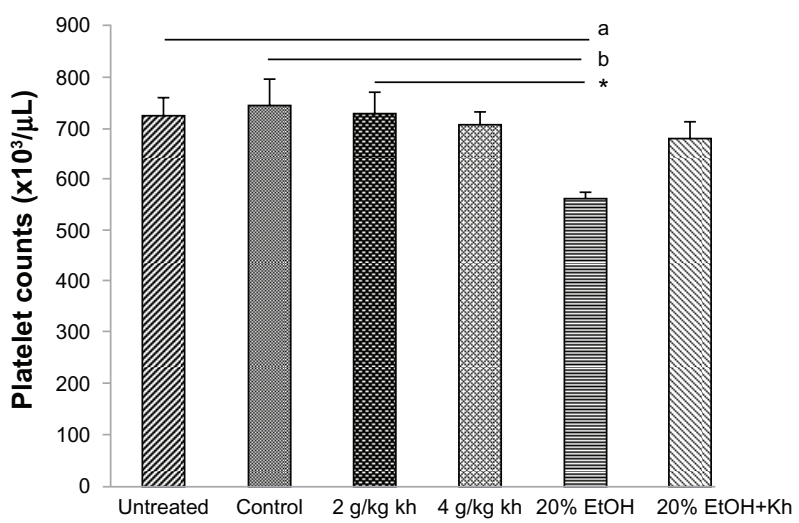

B

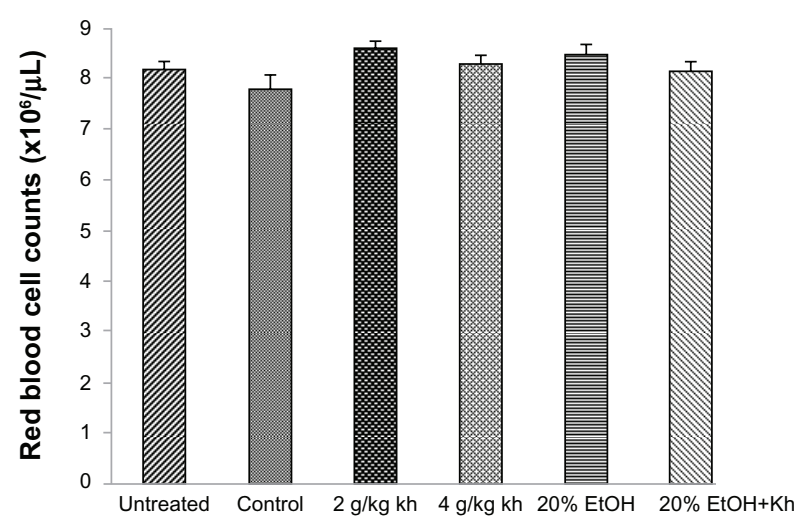

D

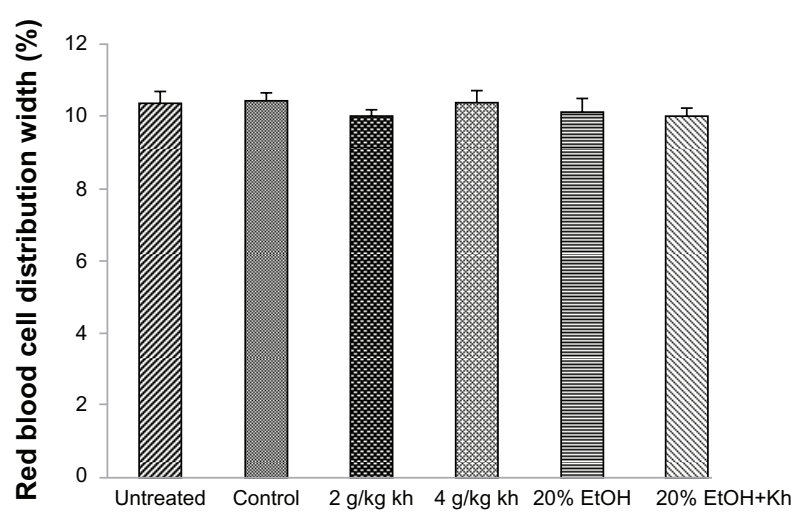

Figure 2 Blood cell counts of male rats after 28 days of treatment.

Notes: (A) White blood cell counts of male rats after 28 days of $2 \mathrm{~g} / \mathrm{kg}$ khat, $4 \mathrm{~g} / \mathrm{kg}$ khat, $20 \%$ ethanol, $20 \%$ ethanol plus khat, control, and no treatment, shown as mean \pm standard error of the mean. There was no statistical difference between the treatment groups. (B) Red blood cell counts of male rats after 28 days of $2 \mathrm{~g} / \mathrm{kg} \mathrm{khat}, 4 \mathrm{~g} / \mathrm{kg}$ khat, $20 \%$ ethanol, $20 \%$ ethanol plus khat, control, and no treatment. There was no statistical difference between the treatment groups. (C) Platelet counts of male rats after 28 days of $2 \mathrm{~g} / \mathrm{kg}$ khat, $4 \mathrm{~g} / \mathrm{kg}$ khat, $20 \%$ ethanol, $20 \%$ ethanol plus khat, control, and no treatment. Ethanol treatment significantly reduced the platelet count compared to $2 \mathrm{~g} / \mathrm{kg}$ khat treatment and control and untreated rats; ${ }^{\mathrm{a}} \mathrm{P}<0.05$, comparing $20 \%$ ethanol and untreated animals; ${ }^{\mathrm{b}} \mathrm{P}<0.05$, comparing $20 \%$ ethanol and control animals; $* \mathrm{P}<0.05$, comparing $20 \%$ ethanol and $2 \mathrm{~g} / \mathrm{kg}$ khat. (D) Red blood cell distribution width of different treatments at $28 \mathrm{days}$ of $2 \mathrm{~g} / \mathrm{kg} \mathrm{khat}, 4 \mathrm{~g} / \mathrm{kg} \mathrm{khat}, 20 \%$ ethanol, $20 \%$ ethanol plus khat, control, and no treatment. There was no statistical difference between the treatment groups. Abbreviations: kh, khat; EtOH, ethanol. 
critical $x^{2}, 5 d f$, for $\alpha$ of $\left.0.05=11.07 ; P=0.018\right)$. Ethanol treatment significantly reduced the platelet count compared to $2 \mathrm{~g} / \mathrm{kg}$ khat treatment $(P<0.05)$, significantly reduced the platelet count compared to control $(P<0.05)$, and significantly reduced the platelet count compared to untreated rats $(P<0.05)$ (Figure 2C).

\section{Hematological indices}

As shown in Figure 3A-D, rats treated for 28 days with $2 \mathrm{~g} / \mathrm{kg}$ khat, $4 \mathrm{~g} / \mathrm{kg}$ khat, $20 \%$ ethanol, and $20 \%$ ethanol plus khat did not show significant differences in MCV, $\mathrm{MCH}$, mean corpuscular hemoglobin concentration (MCHC) or mean platelet volume (MPV); however, the effect of treatment on MPV values approached significance $(P=0.0821)$. Additionally, as shown in Figure 4A, there was a significant effect of treatment on hemoglobin levels

A

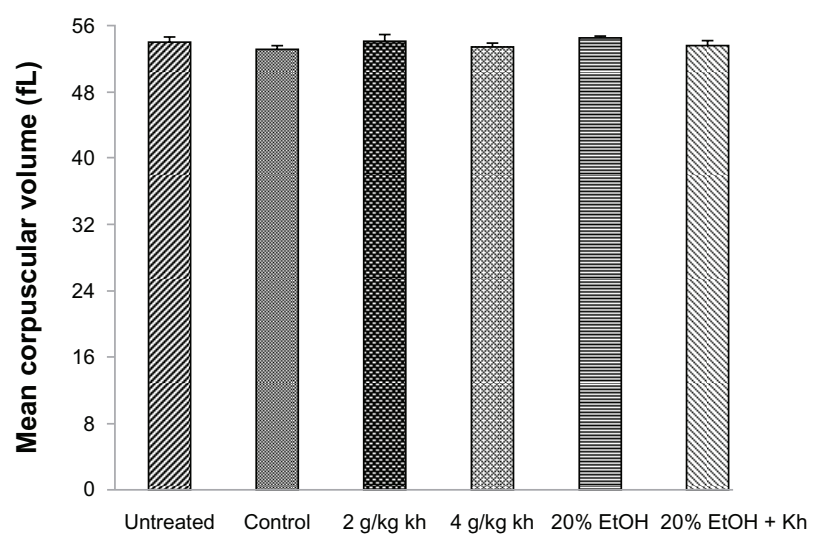

C

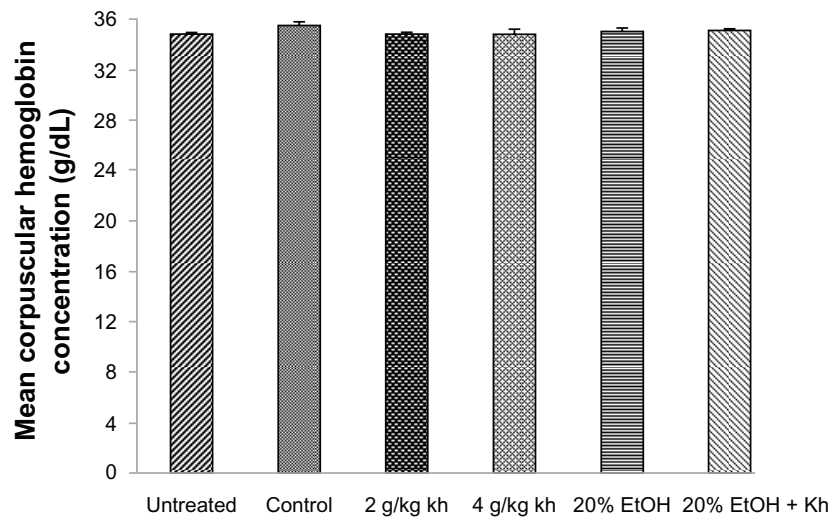

$\left(\mathrm{F}_{(5,49)}=3.78, P=0.0057\right)$. Hemoglobin levels of rats treated with $2 \mathrm{~g} / \mathrm{kg}$ khat significantly increased compared to control treatment $(P<0.05, t=3.786)$ and hemoglobin levels for the $20 \%$ ethanol-treated rats also significantly increased compared to controls $(P<0.05, t=3.425)$ (Figure 4A). Furthermore, there was a significant effect of treatment on hematocrit values $\left(\mathrm{F}_{(5,49)}=2.98, P=0.019\right)$. Hematocrit values of rats treated with $2 \mathrm{~g} / \mathrm{kg}$ khat significantly increased compared to control treatment $(P<0.05$, $t=3.439$ ) (Figure 4B).

\section{Clinical chemistry}

\section{Serum enzymes}

Measurements of serum amylase, ALP, AST, and ALT values showed no statistically significant differences between the treatment groups (Figure 5). However, there was a trend
B

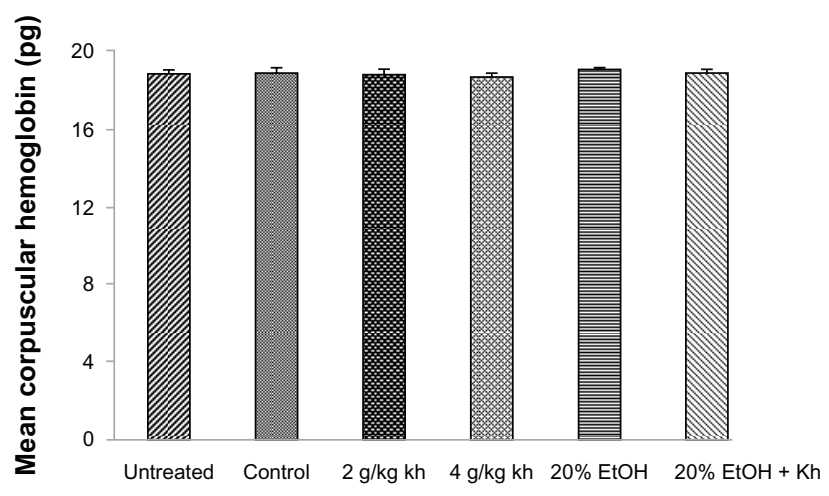

D

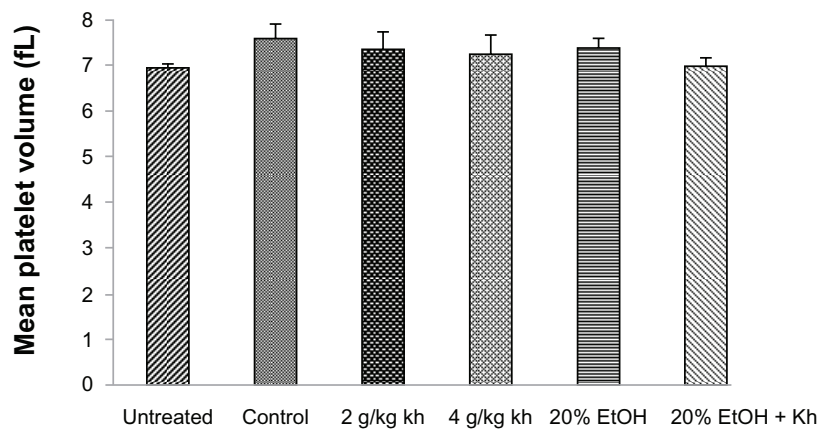

Figure 3 Mean corpuscular values of male rats after 28 days of treatment.

Notes: (A) Mean corpuscular volume of male rats after 28 days of $2 \mathrm{~g} / \mathrm{kg}$ khat, $4 \mathrm{~g} / \mathrm{kg}$ khat, $20 \%$ ethanol, $20 \%$ ethanol plus khat, control, and no treatment, shown as mean \pm standard error of the mean. There was no statistical difference between the treatment groups. (B) Mean corpuscular hemoglobin of male rats after 28 days of $2 \mathrm{~g} / \mathrm{kg}$ khat, $4 \mathrm{~g} / \mathrm{kg}$ khat, $20 \%$ ethanol, $20 \%$ ethanol plus khat, control, and no treatment. There was no statistical difference between the treatment groups. (C) Mean corpuscular hemoglobin concentration of male rats after 28 days of $2 \mathrm{~g} / \mathrm{kg}$ khat, $4 \mathrm{~g} / \mathrm{kg}$ khat, $20 \%$ ethanol, $20 \%$ ethanol plus khat, control, and no treatment. There was no statistical difference between the treatment groups. (D) Mean platelet volume of male rats after 28 days of $2 \mathrm{~g} / \mathrm{kg} \mathrm{khat}, 4 \mathrm{~g} / \mathrm{kg} \mathrm{khat}, 20 \%$ ethanol, $20 \%$ ethanol plus khat, control, and no treatment. There was no statistical difference between the treatment groups.

Abbreviations: kh, khat; $\mathrm{EtOH}$, ethanol. 

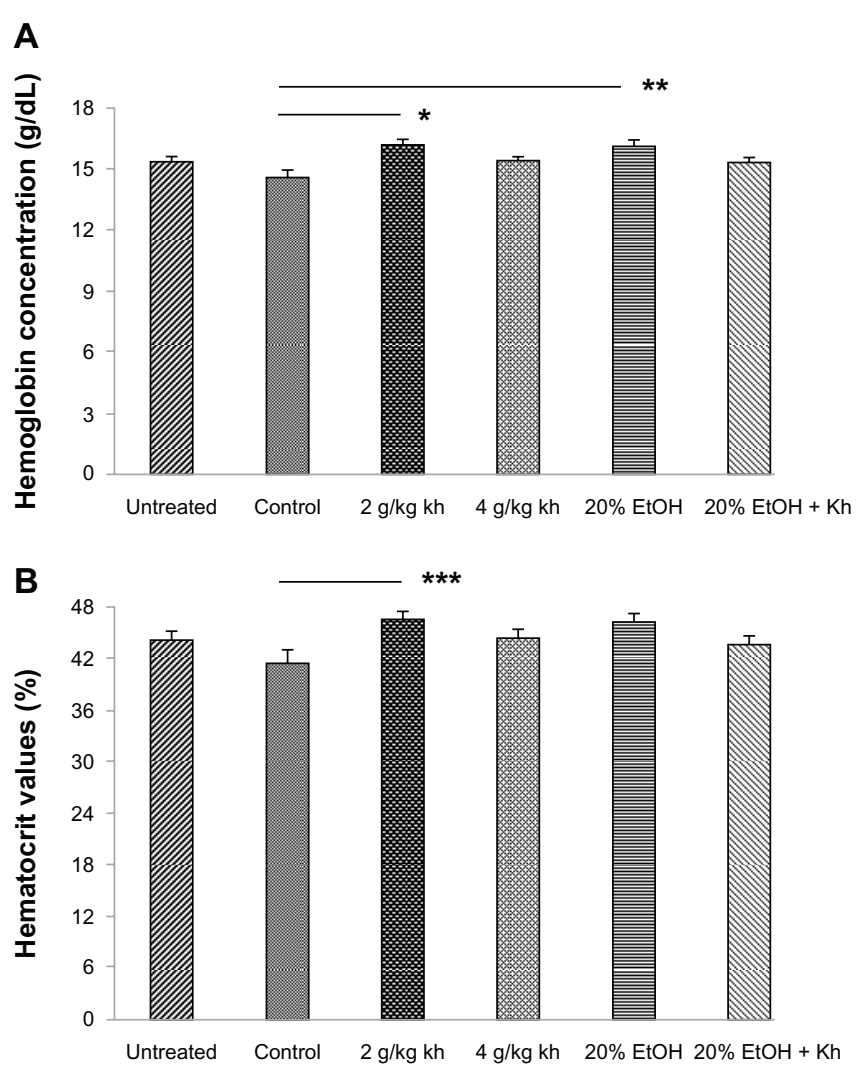

Figure 4 Hemoglobin and hematocrit levels of male rats after 28 days of treatment. Notes: (A) Hemoglobin levels of male rats after 28 days of $2 \mathrm{~g} / \mathrm{kg}$ khat, $4 \mathrm{~g} / \mathrm{kg}$ khat, $20 \%$ ethanol, $20 \%$ ethanol plus khat, control, and no treatment, shown as mean \pm standard error of the mean. Both $2 \mathrm{~g} / \mathrm{kg}$ khat and $20 \%$ ethanol significantly increased $\mathrm{Hb}$ compared to control treatment. $* P<0.05$ comparing $2 \mathrm{~g} / \mathrm{kg}$ khat to control; $* * P<0.05$ comparing $20 \%$ ethanol to control. (B) Hematocrit values of male rats after 28 days of $2 \mathrm{~g} / \mathrm{kg}$ khat, $4 \mathrm{~g} / \mathrm{kg}$ khat, $20 \%$ ethanol, $20 \%$ ethanol plus khat, control, and no treatment. $2 \mathrm{~g} / \mathrm{kg}$ khat significantly increased hematocrit compared to control treatment. $* * * P<0.05$ comparing $2 \mathrm{~g} / \mathrm{kg}$ khat and control.

Abbreviations: kh, khat; EtOH, ethanol.

towards a significant ethanol effect on serum AST levels $(P=0.0611)$; Figure 5C.

\section{Serum proteins}

Measurements of serum levels of creatinine, albumin, HDL, and LDL showed no statistically significant differences between the treatment groups (Figure 6A-D).

\section{Total serum testosterone}

Measurements of total serum testosterone showed no statistically significant differences between the treatment groups (Figure 7).

\section{Discussion}

This study began with the aim of assessing the experimental consequences of combined chronic but short-term khat and ethanol administration on hematological parameters, clinical chemistry, and testosterone levels in male rats. We compared the phytochemical screens of fresh khat aqueous extract, dried khat aqueous extract, and dried methanol extract to get an insight into the appropriate dosing regimen to use, and to evaluate the extent of acute preservation of the phytochemicals contained in khat. The fresh aqueous extract had a phytochemical profile similar to that of the dried methanol extract, but was unlike the dried aqueous extract. However, cathinone, the most active phytochemical in khat, has been identified in dried khat leaves after several years of storage. ${ }^{29}$ This study purposefully chose male rats since prior studies have shown that khat chewing is predominant in men, with prior studies noting that the habit is considered less appealing to women. ${ }^{30}$ Khat use has also been associated with alcohol drinking, cigarette smoking, and the use of other prescription drugs. ${ }^{31}$ As previously described, the present study showed that administration of khat, ethanol, and combined khat and ethanol chronically did not produce weight loss in the juvenile male rats ostensibly because of the short-term anorexiant efficacy of the khat extracts used; ${ }^{22}$ there was however a trend towards weight differences by the end of the present chronic study. This was consistent with a previous study which investigated the chronic liver and hematological effects of khat leaves in a rabbit model.$^{32}$ In that study ground khat leaves added to the diet of rabbits in various concentrations did not alter food intake of the animals or body weight, compared with controls. In the present study, blood samples were collected from trunk blood obtained after decapitation in order to maintain uniform sampling sites, since anatomical location can influence murine hematological parameters. ${ }^{33}$ No anesthesia was administered during decapitation to obtain trunk blood because anesthesia can induce physiological changes that can influence the factors being studied. ${ }^{34}$

The $\mathrm{CBC}$ measured the number of $\mathrm{RBC}, \mathrm{WBC}$, platelets, the total amount of hemoglobin in the blood, and the fraction of the blood composed of RBC (hematocrit). Additional information obtained from the $\mathrm{CBC}$ included the average $\mathrm{RBC}$ size (MCV), the hemoglobin amount per RBC (MCH), and the amount of hemoglobin relative to the size of the cell (hemoglobin concentration) per RBC (MCHC). The hematocrit measures the percentage of the volume of whole blood that is made up of RBCs and depends on their number and size. The significant increase in hematocrit for the $2 \mathrm{~g} / \mathrm{kg}$ of khat group indicated a relative polycythemia, suggesting a decrease in plasma volume without change in RBC mass in which the erythrocytes become more concentrated and which may be either an acute transient condition or a chronic condition. MCV measures the average volume or 
A

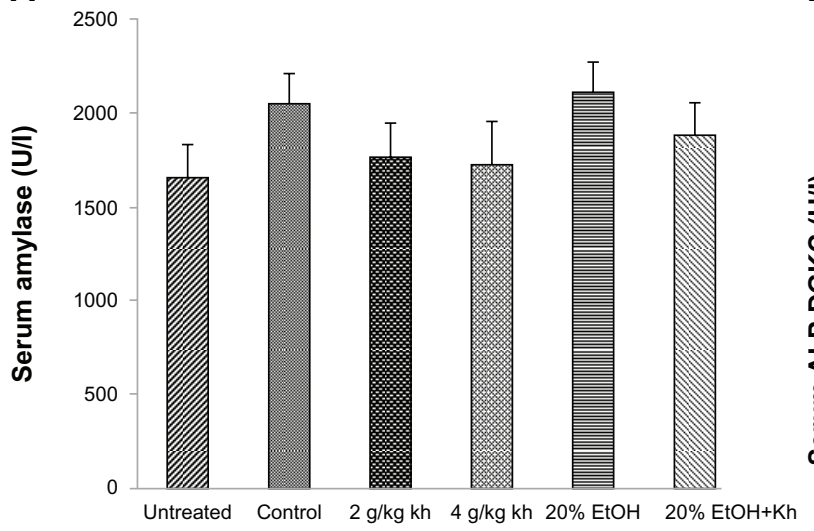

B

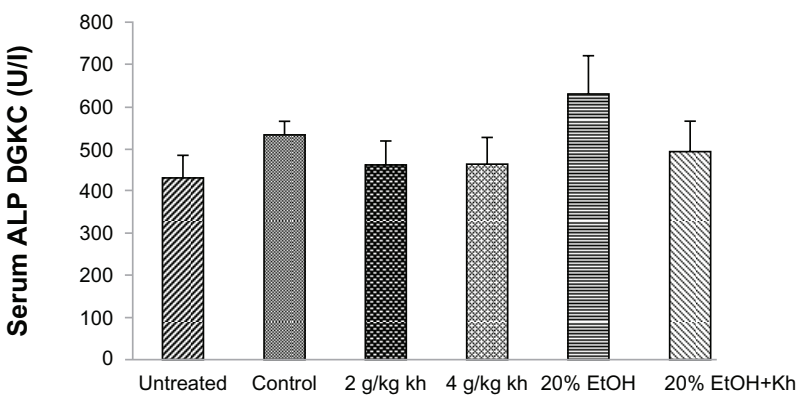

C

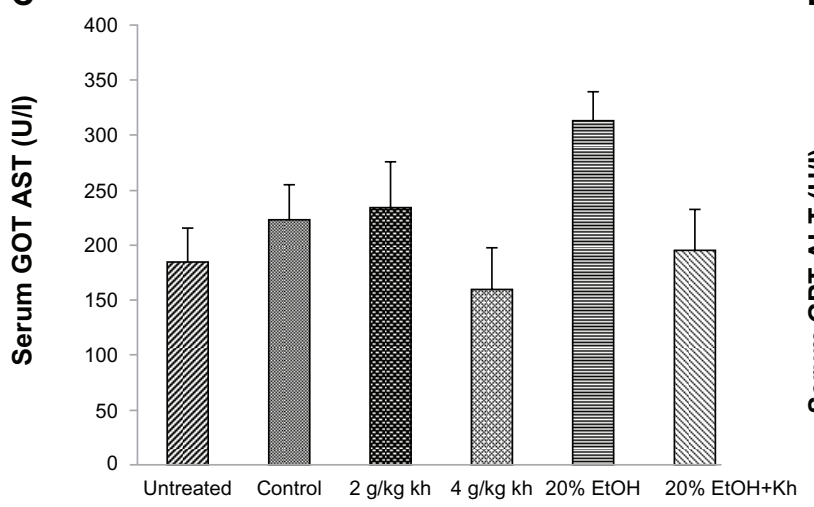

D

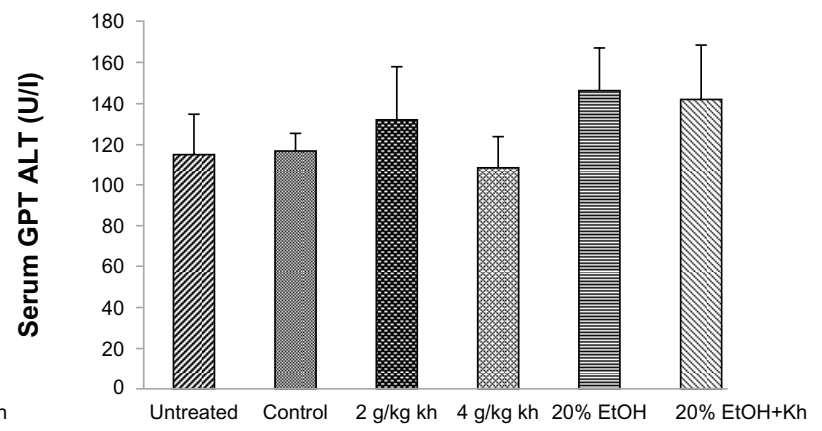

Figure 5 Serum enzyme levels of male rats after 28 days of treatment.

Notes: (A) Serum amylase of male rats after 28 days of $2 \mathrm{~g} / \mathrm{kg}$ khat, $4 \mathrm{~g} / \mathrm{kg}$ khat, $20 \%$ ethanol, $20 \%$ ethanol plus khat, control, and no treatment, shown as mean \pm standard error of the mean. There was no statistical difference between the treatment groups. (B) Serum alkaline phosphatase of male rats after 28 days of $2 \mathrm{~g} / \mathrm{kg} \mathrm{khat}, 4 \mathrm{~g} / \mathrm{kg} \mathrm{khat}$, $20 \%$ ethanol, $20 \%$ ethanol plus khat, control, and no treatment. There was no statistical difference between the treatment groups. (C) Serum aspartate aminotransferase of male rats after 28 days of $2 \mathrm{~g} / \mathrm{kg}$ khat, $4 \mathrm{~g} / \mathrm{kg}$ khat, $20 \%$ ethanol, $20 \%$ ethanol plus khat, control, and no treatment. There was no statistical difference between the treatment groups although there was a trend towards a significant ethanol effect $(P=0.06 \mathrm{I})$. (D) Serum alanine aminotransferase of male rats after $28 \mathrm{days}$ of $2 \mathrm{~g} / \mathrm{kg} \mathrm{khat}, 4 \mathrm{~g} / \mathrm{kg} \mathrm{khat}$, $20 \%$ ethanol, $20 \%$ ethanol plus khat, control, and no treatment. There was no statistical difference between the treatment groups. DGKC is a method for the determination of alkaline phosphatase (ALP) from the German Society of Clinical Chemistry [Deutsche Gesellschaft fur Klinische Chemie].

Abbreviations: ALP, alkaline phosphatase; GOT, glutamic oxaloacetic transaminase; AST, aspartate aminotransferase; GPT, glutamic pyruvate transaminase; ALT, alanine aminotransferase; kh, khat; EtOH, ethanol; DGKC, [Deutsche Gesellschaft fur Klinische Chemie]; German Society of Clinical Chemistry method.

size of a single RBC and increases in patients who chronically drink alcohol and so it is used as a tracker of chronic alcohol administration.

In the present study, ethanol alone significantly reduced the platelet count compared to controls and low-dose $(2 \mathrm{~g} / \mathrm{kg})$ khat. Remarkably, the hemoglobin concentration was significantly increased by both low-dose khat and by $20 \%$ ethanol compared to control animals. A recent animal study found evidence for liver dysfunction in both male and female rats given high dose khat $(2 \mathrm{~g} / \mathrm{kg})$ in which the extracts had been obtained after soxhlet methanol extraction of the dried khat leaves; ${ }^{25}$ there was also evidence for renal dysfunction but only in female rats compared to controls. In our study however, freshly prepared khat leaves were used to mimic the more common use of khat. In the assessment of clinical chemistry, measurements were made for serum creatinine, an indicator of renal function; liver function tests, including the serum enzymes AST, ALT, amylase, alkaline phosphatase, and serum albumin; and HDL and LDL.

AST is widely distributed in various organs but has the highest concentration in hepatocytes; this enzyme is involved in the transfer of amino acids and peptides across the cellular membrane and participates in glutathione metabolism, detects liver cell dysfunction, and is a sensitive indicator of hepatobiliary disease and an indicator of heavy and chronic alcohol use. Our study showed a trend towards a significant increase of AST levels by ethanol on chronic (but shortterm) administration. While prior studies on chronic khat toxicity have identified significant elevations in serum AST, ALT, and ALP, and deranged biochemical indicators such as plasma triglycerides and glucose, ${ }^{35,36}$ the present study did not identify evidence indicating that chronic short-term 
A

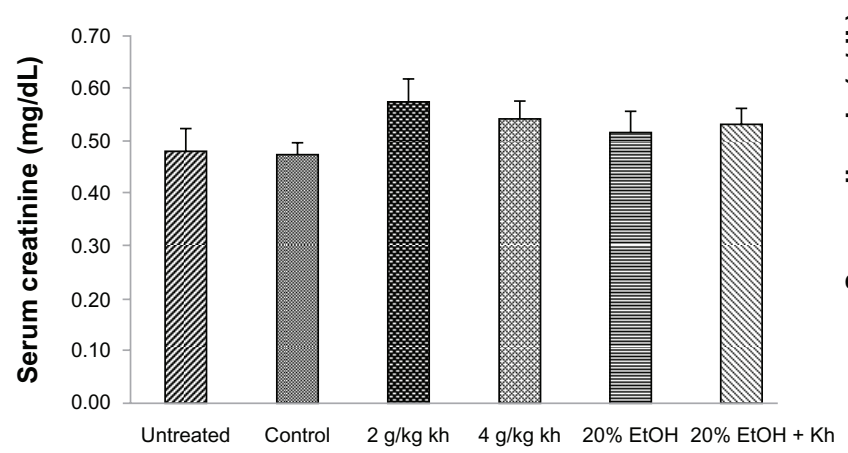

B

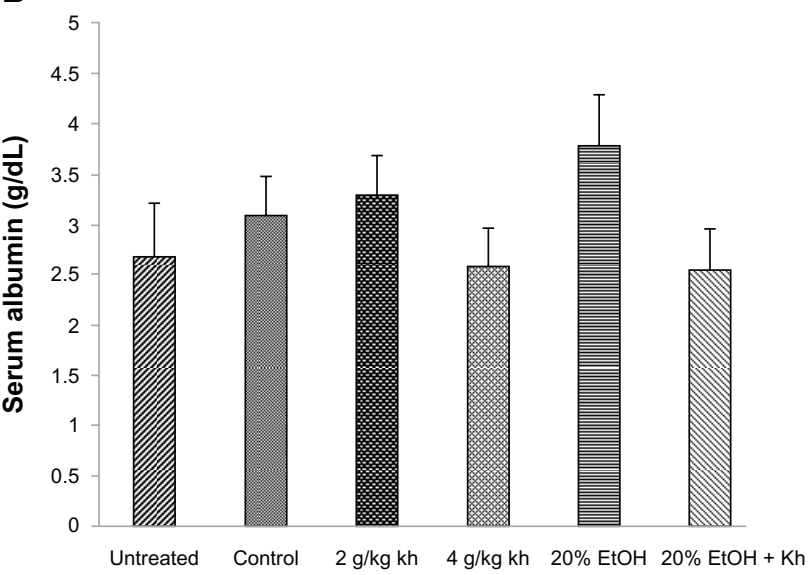

C

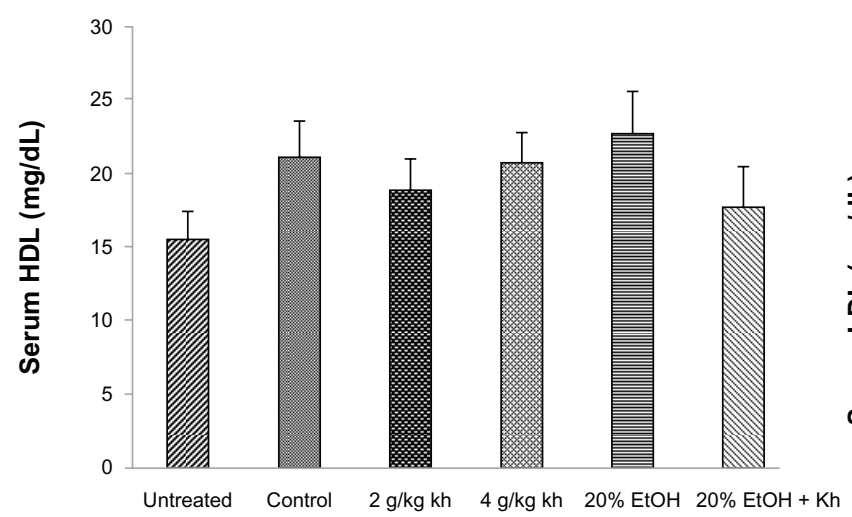

D

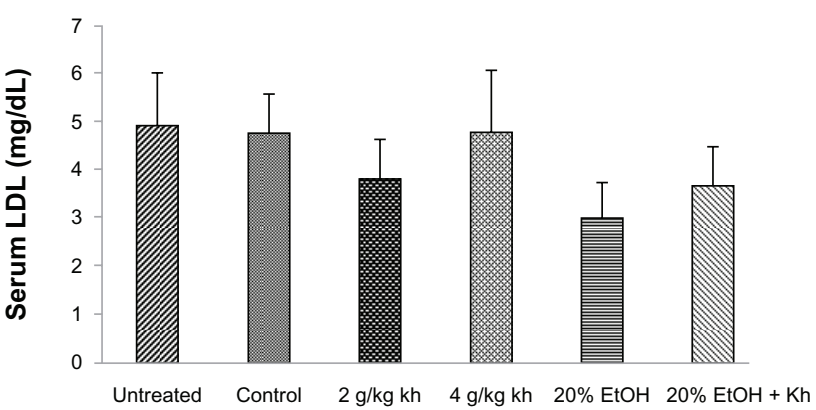

Figure 6 Serum creatinine, albumin and lipoprotein levels of male rats after 28 days of treatment.

Notes: (A) Serum creatinine of male rats after 28 days of $2 \mathrm{~g} / \mathrm{kg} \mathrm{khat,} 4 \mathrm{~g} / \mathrm{kg}$ khat, $20 \%$ ethanol, $20 \%$ ethanol plus khat, control, and no treatment, shown as mean \pm standard error of the mean. There was no statistical difference between the treatment groups. (B) Serum albumin of male rats after 28 days of $2 \mathrm{~g} / \mathrm{kg} \mathrm{khat}, 4 \mathrm{~g} / \mathrm{kg} \mathrm{khat}, 20 \%$ ethanol, $20 \%$ ethanol plus khat, control, and no treatment. There was no statistical difference between the treatment groups. (C) Serum high density lipoprotein of male rats after 28 days of $2 \mathrm{~g} / \mathrm{kg}$ khat, $4 \mathrm{~g} / \mathrm{kg}$ khat, $20 \%$ ethanol, $20 \%$ ethanol plus khat, control, and no treatment. There was no statistical difference between the treatment groups. (D) Serum low density lipoprotein of male rats after 28 days of $2 \mathrm{~g} / \mathrm{kg}$ khat, $4 \mathrm{~g} / \mathrm{kg}$ khat, $20 \%$ ethanol, $20 \%$ ethanol plus khat, control, and no treatment. There was no statistical difference between the treatment groups.

Abbreviations: kh, khat; EtOH, ethanol; LDL, low density lipoproteins; HDL, high density lipoproteins.

khat alone and combined khat and ethanol administration worsen hematological function and clinical chemistry compared to either drug alone. Similar to our chronic study, a chronic long-term study found normal kidney function in rabbits 6 months after exposure to khat, and found a normal hematology profile, except for a mild elevation in WBC count in the female animals on the highest dose studied..$^{35}$ Nevertheless, in the present study, when khat was given concurrently with ethanol, the hematological effects of the latter dissipated, suggesting that an interaction existed between the two substances. The nature of this interaction is presently unknown and could be explored in future mechanistic and other molecular studies.

At least one previous study has found significant dose-dependent depression of serum testosterone by (-)cathinone. ${ }^{16}$ A more recent study found a bi-directional effect of khat on serum testosterone; low-dose khat $(100 \mathrm{mg} / \mathrm{kg}$ ) significantly increased serum testosterone while two other higher doses $(200 \mathrm{mg} / \mathrm{kg}$ and $300 \mathrm{mg} / \mathrm{kg})$ significantly decreased serum testosterone. ${ }^{17}$ In the present study we did not find a significant effect of khat on serum testosterone. It is likely that the disparity between our findings and the study in which khat had a bi-directional effect arises from the difference in the khat extracts administered to the khat-treated animals. The aqueous khat extract used in the present study, intended to mimic customary khat use, apparently had lower concentrations of cathinone than that extracted by the organic solvents (chloroform and ether) used in the study in which khat had a bi-directional effect. Indeed, in the latter study, the $100 \mathrm{mg} / \mathrm{kg}$ khat dose used increased serum testosterone in contrast to the $5 \mathrm{mg} / \mathrm{kg}$ dose of both (-) and (+)cathinone enantiomers used which did not produce any significant 


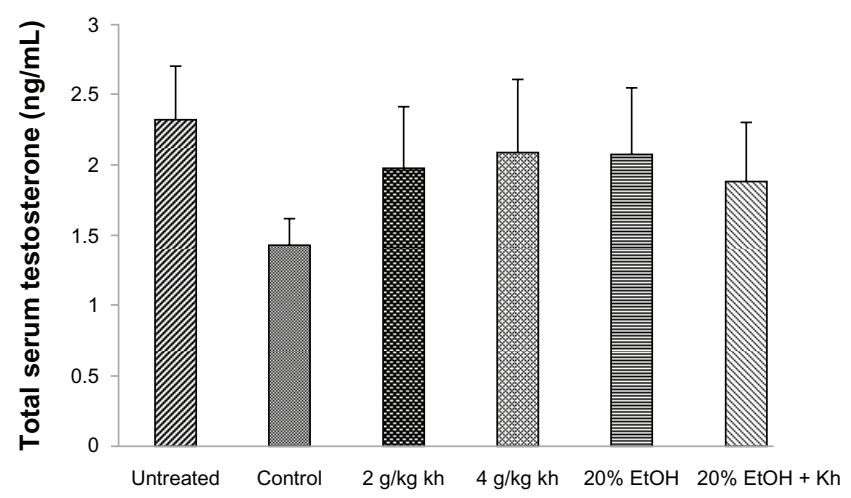

Figure 7 Total serum testosterone in male rats after 28 days of treatment. Notes: Serum testosterone of male rats after 28 days of $2 \mathrm{~g} / \mathrm{kg} \mathrm{khat}, 4 \mathrm{~g} / \mathrm{kg}$ khat, $20 \%$ ethanol, $20 \%$ ethanol plus khat, control, and no treatment, shown as mean \pm standard error of the mean. There was no statistical difference between the treatment groups.

Abbreviations: kh, khat; EtOH, ethanol.

alteration in testosterone levels in male rats. Regardless, higher doses of cathinone (10 and $15 \mathrm{mg} / \mathrm{kg}$ ) have been found to cause a significant decrease in serum testosterone in a dose-dependent manner. ${ }^{16}$ Further studies are needed to delineate the mechanism of khat action on serum testosterone levels, and on the influence of khat on sexual motivation and performance; in contrast to male users, a significant proportion of female users have reported an increase in sexual desire followed by an improvement in sexual performance, an effect that suggests a sex difference in the action of khat on sexual motivation and performance. ${ }^{15}$

Animal studies on the relationship between ethanol administration and testosterone have found biphasic effects of acute and chronic ethanol administration on testosterone. Acute effects of high-dose ethanol $(1.5 \mathrm{~g} / \mathrm{kg})$ caused depressed serum testosterone, ${ }^{37,38}$ while at least one study ${ }^{39}$ found increased serum testosterone after a $2 \mathrm{~g} / \mathrm{kg}$ ethanol dose. Chronic ethanol administration has been found to decrease serum testosterone ${ }^{38}$ by a complex mechanism thought to involve alteration of the hypothalamic-pituitarygonadal axis, ${ }^{38}$ and by a direct toxic effect on Leydig cells, in addition to the accelerated metabolism of testosterone by induction of hepatic microsomal enzymes. The present study used a $4 \mathrm{~g} / \mathrm{kg}$ dose of $20 \%$ ethanol, both for the ethanolonly group and the combined khat and ethanol group. This was intended to mimic the drinking of alcoholic spirits that has been shown among persons who chew khat and drink alcohol concurrently. ${ }^{6}$ In other urban areas in countries such as Ethiopia and Uganda, khat users binge on alcoholic spirits after the khat-chewing session to relieve the mental stimulation resulting from khat, especially at bedtime..$^{40,41} \mathrm{We}$ did not find a significant effect of this high dose of ethanol on serum testosterone, and while the reason for the lack of effect is unclear, it has been established that there is a dosedependent variation of the effect of acute ethanol on testosterone. ${ }^{37,39}$ Further studies may be warranted to determine the effect of chronic low-dose versus high-dose ethanol on serum testosterone. An important caveat to this study was that we used aqueous extracts which, although fresh, did not contain as much of the active phytochemicals as pure cathinone extracts or soxhlet-extracted methanol extracts. However, to offset this limitation, the study was designed to give the fresh khat extract more habitually to mimic the actual custom of khat chewing among users, ${ }^{6}$ in contrast to studies where soxhlet-extracted khat was given only once daily. ${ }^{25}$ Water extracted the phytochemicals less effectively than methanol, implying that the toxic actions of the active principles contained in khat occur in humans via a concerted chronic effect. Chewing of the tender leaves and twigs of khat produces a sweetish taste and an astringent action in the mouth ${ }^{42}$ causing the chewer to drink large amounts of liquids while chewing in order to induce an effect comparable to laboratory water extraction of the active principles. The need for liquids arises because the presence of the strongly astringent tannins produce oral dryness and appear to be little affected by salivary enzymes, since chronic use of khat is characterized by common gastrointestinal side effects such as stomatitis, gastritis, and constipation, and salivary enyzmes are not known to digest cathinone. ${ }^{43}$

As recommended at the World Health Assembly in the Global Strategy to Reduce the Harmful Use of Alcohol, ${ }^{44}$ an important target area for national action is to strengthen the knowledge base on the magnitude and determinants of alcohol-related harm, and on effective interventions to reduce and prevent such harm. This objective should be extended to the knowledge base on the concurrent use of alcohol and drugs such as khat. In conclusion, concurrent chronic but short-term khat and ethanol did not produce worse toxic effects than either drug alone; however, khat and ethanol separately produced limited toxic effects on blood, and appeared to have limited chronic effects on clinical chemistry and testosterone levels in our rat model. Therefore, early clinical intervention to avert the effects of excessive long-term khat and ethanol use can mitigate the harm from these drugs. Eventually, information from studying long-term khat and ethanol coabuse or codependence can help guide decisions for appropriate intervention strategies, both for prevention of khat plus ethanol abuse and to guide strategies designed for appropriate treatment of dependence on these drugs. 


\section{Acknowledgments}

The authors gratefully acknowledge the proficient technical assistance of Deneth Muhereza and David Nkwangu. This work was supported by MESAU-MEPI Programmatic Award (Award Number 1R24TW008886) from the Fogarty International Center. The content is solely the responsibility of the authors and does not necessarily represent the official views of the Fogarty International Center or the National Institutes of Health.

\section{Disclosure}

The authors report no conflicts of interest in this work.

\section{References}

1. Ageely HMA. Health and socio-economic hazards associated with khat consumption. J Family Community Med. 2008;15(1):3-11.

2. Al-Samarraie M, Z Khiabani H, Opdal MS. Khat - a new drug of abuse in Norway. Tidsskr Nor Laegeforen. 2007;127(5):574-576. Norwegian.

3. Nencini P, Ahmed AM. Khat consumption: a pharmacological review. Drug Alcohol Depend. 1989;23(1):19-29.

4. Ihunwo AO, Kayanja FIB, Amadi-Ihunwo UB. Use and perception of the psychostimulant, khat (catha edulis) among three occupational groups in south western Uganda. East Afr Med J. 2004;81(9): 468-473.

5. Anderson D, Beckerleg S, Hailu D, Klein A. The Khat Controversy: Stimulating the Debate on Drugs. Oxford: Berg Publishers; 2007.

6. Beckerleg S. Khat chewing as a new Ugandan leisure activity. Journal of East African Studies. 2009;3(1):42-54.

7. Beckerleg S. "Idle and disorderly" khat users in Western Uganda. Drugs: Education, Prevention, and Policy. 2010;17(4):303-314.

8. Kebede D, Alem A, Mitike G, et al. Khat and alcohol use and risky sex behaviour among in-school and out-of-school youth in Ethiopia. BMC Public Health. 2005;5:109.

9. Manghi RA, Broers B, Khan R, Benguettat D, Khazaal Y, Zullino DF. Khat use: lifestyle or addiction? J Psychoactive Drugs. 2009;41(1): 1-10.

10. Hassan NA, Gunaid AA, Murray-Lyon IM. Khat (Catha edulis): health aspects of khat chewing. East Mediterr Health J. 2007;13(3): 706-718.

11. Ali WM, Al Habib KF, Al-Motarreb A, et al. Acute coronary syndrome and khat herbal amphetamine use: an observational report. Circulation. 2011;124(24):2681-2689.

12. Ali WM, Zubaid M, Al-Motarreb A, et al. Association of khat chewing with increased risk of stroke and death in patients presenting with acute coronary syndrome. Mayo Clin Proc. 2010;85(11): 974-980.

13. Al-Habori M. The potential adverse effects of habitual use of Catha edulis (khat). Expert Opin Drug Saf. 2005;4(6):1145-1154.

14. Al-Motarreb A, Al-Habori M, Broadley KJ. Khat chewing, cardiovascular diseases and other internal medical problems: the current situation and directions for future research. J Ethnopharmacol. 2010;132(3): 540-548.

15. Elmi AS. The chewing of khat in Somalia. J Ethnopharmacol. 1983;8(2):163-176.

16. Islam MW, Tariq M, Ageel AM, el-Feraly FS, Al-Meshal IA, Ashraf I An evaluation of the male reproductive toxicity of cathinone. Toxicology. 1990;60(3):223-234

17. Mohammed A, Engidawork A. Reproductive parameters are differentially altered following subchronic administration of Catha edulis F. (Khat) extract and cathinone in male rats. J Ethnopharmacol. 2011;134(3):977-983.
18. World Health Organization. Global Status Report on Alcohol and Health. Geneva: World Health Organization; 2011. Available from: http://www.who.int/substance_abuse/publications/global_alcohol_ report/msbgsruprofiles.pdf. Accessed May 18, 2013.

19. Roerecke M, Rehm J. Ischemic heart disease mortality and morbidity rates in former drinkers: a meta-analysis. Am J Epidemiol. 2011;173(3): 245-258.

20. Rehm J, Baliunas D, Borges GL, et al. The relation between different dimensions of alcohol consumption and burden of disease: an overview. Addiction. 2010;105(5):817-843.

21. Rehm J, Mathers C, Popova S, Thavorncharoensap M, Teerawattananon Y, Patra J. Global burden of disease and injury and economic cost attributable to alcohol use and alcohol-use disorders. Lancet. 2009;373(9682): 2223-2233.

22. Alele PE, Rujumba JB. Khat (Catha edulis) and ethanol co-dependence modulate seizure expression in a pentylenetetrazol seizure model. J Ethnopharmacol. 2011;137(3):1431-1436.

23. Widler P, Mathys K, Brenneisen R, Kalix P, Fisch HU. Pharmacodynamics and pharmacokinetics of khat: a controlled study. Clin Pharmacol Ther. 1994;55(4):556-562.

24. Odebiyi OO, Sofowora EA. Phytochemical screening of Nigerian medicinal plants II. Lloydia. 1991;41(3):234-246.

25. Alsalahi A, Abdulla MA, Al-Mamary M, et al. Toxicological Features of Catha edulis (Khat) on Livers and Kidneys of Male and Female Sprague-Dawley Rats: A Subchronic Study. Evid Based Complement Alternat Med. 2012;2012:829401.

26. Devaud LL, Matthews DB, Morrow AL. Gender impacts behavioral and neurochemical adaptations in ethanol-dependent rats. Pharmacol Biochem Behav. 1999;64(4):841-849.

27. Elmi AS. Khat and blood glucose levels in man. J Ethnopharmacol. 1983;8(3):331-4.1983.

28. Halbach H. Medical aspects of the chewing of khat leaves. Bull World Health Organ. 1972;47(1):21-29.

29. Chappell JS, Lee MM. Cathinone preservation in khat evidence via drying. Forensic Sci Int. 2010;195(1-3):108-120.

30. Almedo AM, Abraham S. Women, moral virtue and Tchat-chewing. In: McDonald M, editor. Gender, Drink and Drugs. Oxford: Berg Publishers; 1994:249-259.

31. Heather N, Miller WR, Greeley J, editors. Self-Control and the Addictive Behaviours. Sydney, Australia: Maxwell MacMillan; 1991.

32. Al-Mamary M, Al-Habori M, Al-Aghbari AM, Baker MM. Investigation into the toxicological effects of Catha edulis leaves: a short term study in animals. Phytother Res. 2002;16(2):127-132.

33. Nemzek JA, Bolgos GL, Williams BA, Remick DG. Differences in normal values for murine white blood cell counts and other hematological parameters based on sampling site. Inflamm Res. 2001;50(10): 523-527.

34. Gothelf A, Hojman P, Gehl J. Change in hemoglobin levels due to anesthesia in mice: an important confounder in studies on hematopoietic drugs. Biol Proced Online. 2009;11(1):325-330.

35. Al-Habori M, Al-Aghbari A, Al-Mamary M, Baker M. Toxicological evaluation of Catha edulis leaves: a long term feeding experiment in animals. J Ethnopharmacol. 2002;83(3):209-217.

36. Al-Habori M, Al-Mamary M. Long-term feeding effects of Catha edulis leaves on blood constituents in animals. Phytomedicine 2004;11(7-8): 639-644.

37. Apter SJ, Eriksson CJ. The effect of alcohol on testosterone concentrations in alcohol-preferring and non-preferring rat lines. Alcohol Clin Exp Res. 2003;27(7):1190-1193.

38. Cicero TJ, Badger TM. Effects of alcohol on the hypothalamic-pituitarygonadal axis in the male rat. J Pharmacol Exp Ther. 1977;201(2): 427-433.

39. Alomary AA, Vallée M, O’Dell LE, Koob GF, Purdy RH, Fitzgerald RL. Acutely administered ethanol participates in testosterone synthesis and increases testosterone in rat brain. Alcohol Clin Exp Res. 2003;27(1): 38-43.

40. Gebissa E. Scourge of Life or an Economic Lifeline? Public Discourses on Khat (Catha edulis) in Ethiopia. Subst Use Misuse. 2008;43(6): 784-802. 
41. Beckerleg S. What harm? Kenyan and Ugandan perspectives on khat. African Affairs. 2006;105(419):219-241.

42. Osol A, Farrar GE, editors. The Dispensatory of the United States of America. 25th ed. Philadelphia, PA: JB Lippincott Company; 1955.

43. Nencini P, Ahmed AM, Elmi AS. Subjective effects of khat chewing in humans. Drug Alcohol Depend. 1986;18(1):97-105.
44. World Health Organization. Global survey of alcohol and health. Management of substance abuse. World Health Organization; 2010. Available from: http://www.who.int/substance_abuse/en/. Accessed May 5, 2013.

\section{Publish your work in this journal}

The Journal of Experimental Pharmacology is an international, peerreviewed, open access journal publishing original research, reports, reviews and commentaries on all areas of laboratory and experimental pharmacology. The manuscript management system is completely online and includes a very quick and fair peer-review system.

Visit http://www.dovepress.com/testimonials.php to read real quotes from published authors. 